\title{
Influence of Tympanosclerosis on Graft Uptake and Hearing Status in Patients Undergoing Underlay Myringoplasty
}

\author{
Prasad PL, ${ }^{1}$ Bhattarai $\mathrm{H}^{2}$ \\ 'Department of ENT, Head and Neck Surgery, National Academy of Medical Sciences, Bir Hospital, Kathmandu, ${ }^{2}$ Department \\ of ENT, Head and Neck Surgery, Tribhuvan University Teaching Hospital, Kathmandu, Nepal
}

\section{ABSTRACT}

Background: To assess the influence of tympanosclerosis on graft uptake and hearing status in patients undergoing underlay myringoplasty.

Methods: Patients $\geq 12$ years of age with the diagnosis of chronic suppurative otitis media tubo-tympanic type were included in this study. All patients participated in the study had undergone pre and postoperative pure tone audiometric evaluation and were divided into two groups, a study and a control, depending on the presence or absence of tympanosclerotic plaques. All patients underwent underlay myringoplasty and follow up was done after 10 weeks to note graft uptake and postoperative hearing evaluation.

Results: Graft uptake was noted to be $96.1 \%$ in study group and $94.9 \%$ in control group. Similarly, graft uptake was noted in $96.36 \%$ where tympanosclerotic plaques were completely removed and in $95.23 \%$ where tympanosclerotic plaques were either partially removed or left as such. Post Operative average hearing gain in study and control group was $12.1 \mathrm{~dB}$ and $15.9 \mathrm{~dB}$ respectively. While comparing postoperative hearing gain in cases where tympanosclerotic plaques were completely removed to those in whom tympanosclerotic plaques were either completely removed or left as such, it was $12.31 \mathrm{~dB}$ in former and $13.67 \mathrm{~dB}$ in later group, which was statistically non significant with $\mathrm{P}$ value of 0.83 .

Conclusions: Tympanosclerotic plaques, if removed as far as practicable, has no effect on either graft uptake and post operative hearing results in patient under going underlay myringoplasty.

Key words:chronic suppurative otitis media tubo tympani type, puretone, audiogram, tympanosclerosis.

\section{INTRODUCTION}

Chronic suppurative otitis media (CSOM TT) is one of the commonest ear diseases in developing countries. Its prevalence in Nepal is $7.2 \% .{ }^{1}$ So far there is no universally accepted definition of tubo-tympanic disease. CSOM tubo-tympanic is a stage of ear disease in which there is chronic infection of the middle ear cleft or non intact tympanic membrane and discharge, otorrhoea for at least preceding two weeks. ${ }^{2}$

CSOM TT is classified into tubo-tympanic and atticoantral disease. ${ }^{3}$ It is a benign chronic middle ear infection where there is no danger of developing intracranial

Correspondence: Dr. PL Prasad, Department of ENT, Head and Neck Surgery, National Academy of Medical Sciences, Bir Hospital, Kathmandu, Nepal. Phone: 9803471236, Email: prasadpannalal@yahoo.com 
Influence of Tympanosclerosis on Graft Uptake and Hearing Status in Patients Undergoing Underlay Myringoplasty

complications and is characterized by perforation in the tympanic membrane and infection is limited to the middle ear mucosa.

CSOM TT of longer duration is associated with a condition called tympanosclerosis which incidence varies from 3$43 \% .^{4-7}$ It is characterized by hyaline degeneration of fibrous layer of tympanic membrane and middle ear mucosa. ${ }^{8,9}$

The exact aetiopathogenesis of this condition is unknown. Different hypothesis regarding its development are repeated middle ear cleft infection, immunological response of lamina propria of tympanic membrane and middle ear mucosa to its infection.

\section{METHODS}

This prospective longitudinal study was done from December 2004 to June 2006 at the Department of ENT, HNS, Tribhuvan University Teaching Hospital, Maharajgunj Kathmandu Nepal. Ethical approval and patient consent was taken. Patient aged 12 years or more with either sex having chronic suppurative otitis media - tubo-tympanic (inactive stage) already planned for myringoplasty, were included in the study. The cases of tubo-tympanic disease in active stage, having sensory neural hearing loss and revision myringoplasty were excluded from the study.

One day prior to surgery, all patients underwent pre operative work for otoscopic evaluation of ear.Pure tone audiogram (PTA) for air conduction threshold of hearing taking an average of $500,1000,2000 \mathrm{HZ}$ frequencies was done by a senior audiologist in a sound treated room. PTA done one week prior to surgery by the same audiologist was also taken into consideration. Postoperative PTA to evaluate air conduction hearing threshold was performed after 10 weeks of operation. Total 176 patients were included in the study and divided into a study and a control group depending on the presence and absence of tympanosclerosis respectively. Total number of patients in study group was 81 and 95 in control group.

All patients underwent underlay myringoplasty by consultant otologists, mostly by permeatal approach and were discharged on fifth day of operation with an advice of oral Amoxycillin for total of 10 days. Ear pack removed on $10^{\text {th }}$ day followed by Betnor ear drop and aural precautions. In some of the cases surgery was done on out patient department (OPD) basis as well. All patients were strictly advised to come for follow up at $10^{\text {th }}$ week of operation. During operation, extent of tympanosclerotic plaques in tympanic membrane were noted but those in middle ear cavity were ignored and not included in the study. During procedure, tympanosclerotic plaques were excised as much as practicable and tympanic membrane perforation grafted with temporalis muscle fascia.

On follow up immediately after ten weeks of operation, tympanic membrane was evaluated otoscopically for graft uptake. The grafted ear with pus and residual perforation was considered as graft failure. PTA was done to know the post operative air conduction hearing threshold taking an average of 500, 1000, $2000 \mathrm{HZ}$ frequencies. PTA was done by the same audiologist if not, by other senior audiologists.

\section{RESULTS}

During one year and six months period, total number of myringoplasty done at the centre was 349 , out of which 257 were the patients of CSOM tubo-tympanic disease without tympanosclerosis and 92 with tympanosclerosis.

Total 176 patients were included in the study among which 95 were enrolled as control group and 81 as study group. Follow up rate in control group was 78 (82.10\%) and $76(93.82 \%)$ in study group. The average age of patients in control group was $23 \pm 8$ years with the range 13 - 48 years where as in the study group; it was $24 \pm$ 8.5 years with the range 12 - 45 years. Regarding sex distribution male to female ratio was $1.4: 1$ in control group and 0.72:1 in study group.

The average pre and postoperative air conduction threshold in control group was $34.3 \mathrm{~dB}$ and $18.4 \mathrm{~dB}$ respectively with a net hearing gain of $15.9 \mathrm{~dB}$. In study group, it was found to be $31.0 \mathrm{~dB}$ and $18.9 \mathrm{~dB}$ respectively with net hearing gain of $12.1 \mathrm{~dB}$. The difference in net hearing gain was not significant (Table 1).

Pre operative and post operative air conduction threshold was measured and compared between cases in whom tympanosclerotic plaques completely removed to those cases in whom tympanosclerotic plaques were either partially removed or left as such.

Pre operative and post operative hearing threshold was $31.76 \mathrm{~dB}$ and $19.45 \mathrm{~dB}$ respectively with net hearing gain of $12.31 \mathrm{~dB}$ in former cases where as pre and post operative air conduction threshold was $31.19 \mathrm{~dB}$ and $17.52 \mathrm{~dB}$ respectively with net hearing gain of $13.67 \mathrm{~dB}$ in the latter. The observed difference was found non significant (Table 2).

Graft uptake was seen in 74 (94.9\%) cases under control group and in $73(96.1 \%)$ study group. The difference was statistically not significant (Table 3 , Figure 1 ).

Comparing graft uptake rate in cases in whom tympanosclerosis was completely removed to those in whom it was either partially removed or left as such and 
Influence of Tympanosclerosis on Graft Uptake and Hearing Status in Patients Undergoing Underlay Myringoplasty

Table 1. Comparison between Study and Control Group in Relation to Preoperative and Post-operative Air Conduction
Threshold.
\begin{tabular}{|lcccc|} 
Group & $\begin{array}{c}\text { Pre-operative pure tone } \\
\text { audiogram (dB) }\end{array}$ & $\begin{array}{c}\text { Post-operative pure tone } \\
\text { audiogram (dB) }\end{array}$ & Net gain (dB) \\
\hline Study & Mean \pm SD & $31.0 \pm 12.9$ & $18.9 \pm 15.0$ & $12.1 \pm 13.4$ \\
Control & Mean \pm SD & $34.3 \pm 16.1$ & $18.4 \pm 13.4$ & $15.9 \pm 13.5$ \\
P value from Z test & & 0.17 (NS) & 0.81 (NS) & 0.08 (NS) \\
\hline
\end{tabular}

$\mathrm{SD}=$ standard deviation, $\mathrm{NS}=$ not significant

Table 2. Comparison between Pre-operative and Post-operative Air Conduction Hearing Threshold after Partial or Complete Removal of Tympanosclerotic Plaques

\begin{tabular}{|lcccc|}
\multicolumn{2}{|l}{ Removal of tympanosclerotic plaques } & \multicolumn{1}{c}{$\begin{array}{c}\text { Pre-operative pure tone } \\
\text { audiogram }(\mathrm{dB})\end{array}$} & $\begin{array}{c}\text { Post-operative pure tone } \\
\text { audiogram }(\mathrm{dB})\end{array}$ & Net gain $(\mathrm{dB})$ \\
\hline Complete & Mean \pm SD & $31.76 \pm 11.98$ & $19.45 \pm 15.52$ & $12.31 \pm 13.29$ \\
Partial or left as such & Mean \pm SD & $31.19 \pm 16.31$ & $17.52 \pm 13.64$ & $13.67 \pm 14.11$ \\
p value from Z test & & 0.87 (NS) & 0.62 (NS) & 0.83 (NS) \\
\hline
\end{tabular}

$\mathrm{SD}=$ standard deviation, NS = not significant

was found successful in $53(96.36 \%)$ in the former and in $20(95.23 \%)$ in the later with $P$ value 1.0. (Table 4 ).

Table 3. Graft Uptake in Study and Control Groups.

\begin{tabular}{|lccc|}
\hline \multirow{2}{*}{ Graft } & \multicolumn{2}{c}{ Group } & P value \\
\hline Taken up & $73(96.1 \%)$ & $74(94.9 \%)$ & \\
Not Taken up & $3(3.9 \%)$ & $4(5.1 \%)$ & $1.0(\mathrm{NS})$ \\
Total & $76(100 \%)$ & $78(100 \%)$ & \\
\hline
\end{tabular}

NS = not significant

Table 4. Graft Uptake Rates after Complete and Partial Removal of Tympanosclerotic Plaques

Tympanosclerotic plaques Graft uptake rate $\mathrm{P}$ value Completely removed 53 (96.36\%) $(n=55)$

Partially removed or left $20(95.23 \%)$ as such $(\mathrm{n}=21)$

NS = not significant

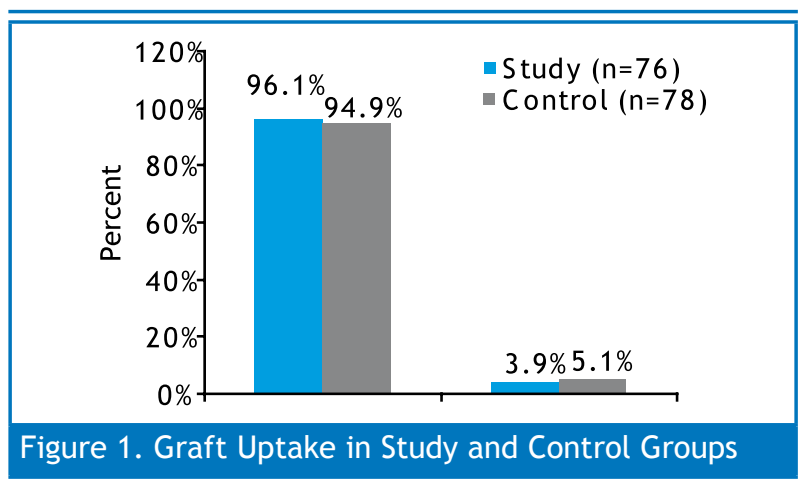


Influence of Tympanosclerosis on Graft Uptake and Hearing Status in Patients Undergoing Underlay Myringoplasty

of those ears in which tympanosclerotic plaques were either partially removed or left as such, statistically no significant difference was noted. The ears with complete removal of tympanosclerotic plaques had an average post operative hearing gain of $12.31 \mathrm{~dB}$; where as in ears with partial removal of tympanosclerotic plaques or tympanosclerotic plaques left as such had an average post operative hearing gain of $13.6 \mathrm{~dB}$. Tympanosclerotic plaques removal was done as far as possible and no attempt was done to remove it; if it was far away from the margin of perforation. The mobility of tympanic membrane is greatly reduced leading to marked hearing loss when tympanosclerotic plaques had involve large area of tympanic membrane or adherent to the bony annulus, handle of malleus or promontory. ${ }^{10}$ The degree of hearing loss associated with tympanosclerosis depends on the extent of tympanosclerotic involvement of the ossicular chain. ${ }^{11}$ All of the patients included in the study were operated by consultants only. Mostly the operation were done by permeatal approach but in few cases, it was done by post aural or end aural approach as well depending upon surgeons choice or else anterior margin of perforation was not seen.

Invariably, temporalis muscle fascia was used as graft materials in all the cases. The technique used for operation was underlay, the most popular technique of myringoplasty worldwide nowadays. All operations were done in dry ears only. Moist ears or ears with pus in middle ear cavity were not included in the study.

Comparing graft uptake rate in the study and the control group, it was $96.1 \%$ and $94.7 \%$ respectively, the difference being statistically non significant with $P$ value of 1.0. Similarly, graft uptake rate in cases; where tympanosclerotic plaques were completely removed was $96.36 \%$ and it was $95.23 \%$ in those cases where tympanosclerotic plaques were either partially removed or left as such. There was no significant difference in the graft uptake rate between tympanosclerotic and non tympanosclerotic groups, in contrast to our study findings, they had reported graft uptake rate of $53.5 \%$ and $84.4 \%$ in patients of CSOM TT type disease with tympanosclerosis and without tympanosclerosis respectively. ${ }^{10}$ This difference was highly significant $(P<0.05)$. However, they have not mentioned that whether the TS plaques were left as such or were removed. However a more robust and long term research study may reveal further information about the study.

\section{CONCLUSION}

Tympanosclerotic plaques, if removed as far as practicable, has no effect on either graft up take or post-operative hearing status in patient undergoing underlay myringoplasty.

\section{REFERENCES}

1. Little P, Bridges A, Guragain RPS, Prasad R, Weir N, Friedman D. Hearing Impairment and ear pathology in Nepal. J Laryngol Otol. 1993 May; 107(5):395-400.

2. World Health Organization. Prevention of hearing impairment from chronic otitis media. [Online]. [cited on Sep 10, 2009] Available from: URL:http://www.who.int/pbd/deafness/en/ chronic_otitis_media.pdf

3. Mills RP. Management of chronic suppurative otitis media. Scott Brown's otolaryngology. 6th ed. Mumbai: Butterwoth Heinemann; 1997.

4. Kroon DF, Strasnick B. Disease of the auricle, external auditory canal and tympanic membrane. Glasscock-Shambaough Surgery of the ear. 5th ed. India: Elsevier; 2003. p. 345-65.

5. Sheey JL, House WF. Tympanosclerosis. Arch Otolaryngology. 1962 Aug;76:151-157.

6. Tos M, Bak-Pedersen K. Middle ear mucosa in tympanosclerosis. J Laryngol Otol. 1974;88:119-26.

7. Wielinga EW, Kuijpers W, Tonnaer EL, Jap PH. An experimental model for tympanosclerosis. A preliminary report. Acta Otolaryngol. 1988 May-Jun;105(5-6):537-42.

8. Bhaya MH, Schachern PA, MorizonoT, Paparella MM. Pathogenesis of tympanosclerosis. Otolaryngol Head Neck Surg. 1993 Sep; 109(3 Pt 1):413-20.

9. Teufert KB, De La Cruz A. Tympanosclerosis: long-term hearing results after ossicular reconstruction. Otolaryngol Head Neck Surg. 2002 Mar;126(3):264-72.

10. Wielinga EW, Kerr AG. Tympanosclerosis. Clin Otolaryngol Allied Sci. 1993 Oct;18(5):341-9.

11. Kamal SA. Surgery of tympanosclerosis. J Laryngol Otol. 1997 Oct;111(10):917-23. 